\title{
Planejamento e controle da produção em uma empresa alimentícia de pequeno porte
}

Jocicleia Bissaro Rodrigues jocicleia.b.r@hotmail.com

Universidade Federal do Espírito Santo (UFES), São Mateus, Espírito Santo, Brasil

Rita de Cassia Feroni rita.feroni@ufes.br

Universidade Federal do Espírito Santo (UFES), São Mateus, Espírito Santo, Brasil

\begin{abstract}
RESUMO
O Planejamento e Controle da Produção (PCP) é fundamental para que uma empresa defina suas metas e estratégias no mercado a fim de criar um plano de gestão para seu bom desempenho. Dessa forma, o objetivo do presente estudo é realizar verificações associadas à gestão de demanda, estoque e capacidade e propor a implantação de um sistema de PCP em uma empresa de pequeno porte do ramo alimentício, situada no Espírito Santo, Brasil. O estudo usou como referências as metodologias de implantação de PCP e análise de processos consolidadas na literatura. Para a execução do trabalho foram realizadas observações diretas do processo produtivo e entrevistas in loco. Os resultados mostraram que a empresa estudada não realiza procedimentos formais de gestão de demanda e estoque, mensuração da capacidade e também rotinas bem definidas, o que resulta em problemas associados ao processo produtivo. Com isso, foi possível seguir os passos de implantação e fornecer as estratégias iniciais para que o PCP possa ser implantado, por meio do desenvolvimento de planilhas eletrônicas associadas à filosofia Kanban e ao Period Batch Control, sem que seja necessária a compra de um software de gestão. Adicionalmente, a investigação, análise, sugestões e simplificações dos processos produtivos realizados no presente trabalho são fontes de informação para pesquisas futuras em situações similares a da empresa estudada.
\end{abstract}

PALAVRAS-CHAVE: Atividades do PCP. Implantação do PCP. Empresa alimentícia. Pequena Empresa. 


\section{INTRODUÇÃO}

Com o aumento da competitividade entre as empresas, os consumidores têm mais opções de escolha no momento da compra e se tornam mais exigentes com relação a vários quesitos, dentre eles prazo de entrega, preço, atendimento personalizado e, principalmente, qualidade (PASQUINI, 2015). Nesse sentido, a empresa que estiver preparada para se destacar em alguns desses pontos perante seus concorrentes conquistará novas fatias do mercado (Gomes; Camilo, 2014). Sendo assim, planejar e controlar a produção são processos essenciais para atender as exigências dos clientes, o que faz as organizações buscarem pelo Planejamento e Controle da Produção (PCP) (PASQUINI, 2015).

Diante disso, elaborar um fluxo de informações/produção e também identificar funções do PCP associadas, por exemplo, a gestão de estoque, planejamento de capacidade e a emissão, programação e acompanhamento de ordens de produção, tornam-se objetivos de estudos científicos (CASTRO, 2018). A fim de melhorar seus processos produtivos, aumentar a lucratividade e diminuir perdas, vários estudos vêm aplicando ferramentas do PCP associadas a gestão de demanda (VERÍSSIMO et al., 2012; SILVA; WERNER, 2016; MENEGHINI et al., 2018; BESSONI et al., 2018), gestão de estoque (GOMES; MILAN, 2017; ARAÚJO et al., 2018; BESSONI et al., 2018; FERREIRA et al., 2019) e gestão de capacidade (ALMEIDA et al., 2016; MOTTA; GOMES, 2017; NUNES et al., 2018).

A aplicação do PCP recai, em sua maioria, sobre grandes empresas e seus sistemas computacionais (softwares) robustos, não havendo espaço para as pequenas instituições, nem para os passos que precedem a implantação de sistemas operacionais e a preparação do ambiente para seu recebimento (BARROS FILHO; TUBINO, 1998). Barbosa et al. (2019) verificaram em seu estudo que seis entre as dez empresas de sua amostra (onde sete eram micro ou pequenas empresas) não utilizavam nenhum software para controle da produção e gestão de estoque ou não sabiam especificar as técnicas utilizadas em suas empresas. Segundo Martins et al. (2015), micro e pequenas empresas possuem em geral estruturas organizacionais razoavelmente simples, com baixa complexidade no mix de produtos, conseguindo assim, realizar o seu planejamento a partir de planilhas eletrônicas.

$O$ processo de inserção de estratégias tradicionais de PCP em pequenas instituições envolve, em teoria, os mesmos conjuntos de atividades relacionadas à administração da produção em qualquer outra empresa. Contudo, na parte prática o cenário é totalmente diferente, uma vez que administrar a produção de pequenas empresas possui sua própria gama de problemas. Somado a isso, o pouco recurso disponível para destinar profissionais a desempenharem funções específicas no processo de gestão e execução faz com que cada colaborador passe a realizar várias atividades diferentes e fora de sua especialização, dificultando os processos de mudança, inclusive de sistemas como o de PCP (SLACK et al., 2015).

Com base nisso, os estudos de Fagundes e Pires (2013), Martins et al. (2015) e Cruz (2018) utilizaram a metodologia proposta por Barros Filho e Tubino (1999) na implantação das rotinas de PCP focada em pequenas e médias empresas, que consiste em estruturar as atividades do PCP que partem desde a definição da equipe responsável pelo projeto até a implantação do sistema ideal. Associado a isso, estudos como os de Godinho Filho e Fernandes (2002), Sagawa et al. (2015) 
e Martins et al. (2015) utilizaram a metodologia de MacCarthy e Fernandes (2000) para classificar e verificar disfunções dos processos produtivos de algumas empresas. Essas metodologias não estão atreladas a nenhum pacote computacional específico e objetiva contemplar a simplificação da fábrica como um todo, o que permite a implantação das rotinas de PCP sem a necessidade de compra de um software, fator que torna mais acessível a busca das pequenas instituições por melhorias em seus processos.

Neste contexto, o objetivo do presente trabalho é realizar verificações na gestão de demanda, gestão de estoque e gestão de capacidade em uma empresa alimentícia do estado do Espírito Santo, denominada Empresa $X$ por sigilo, e propor a implantação do $\mathrm{PCP}$, por meio da aplicação da metodologia proposta por Barros Filho e Tubino (1999) em associação com a metodologia de MacCarthy e Fernandes (2000).

\section{METODOLOGIA}

\section{DESCRIÇÃO DA EMPRESA}

A Empresa X, escolhida para realização do presente trabalho, possui sede no estado do Espírito Santo, e está há 20 anos no mercado atuando com a produção de derivados de mel e própolis, alimentos em cápsulas, chás, shakes e ainda uma linha de suplementos para academia. A Empresa X conta atualmente com 44 funcionários que trabalham de segunda-feira a sexta-feira, 8 horas diárias, em período de demanda normal ou baixa, havendo a inclusão de turno noturno e trabalho aos sábados em momentos de alta demanda. Os colaboradores são dispostos segundo o organograma abaixo em seis níveis hierárquicos (Figura 1).

Figura 1 - Organograma da Empresa X

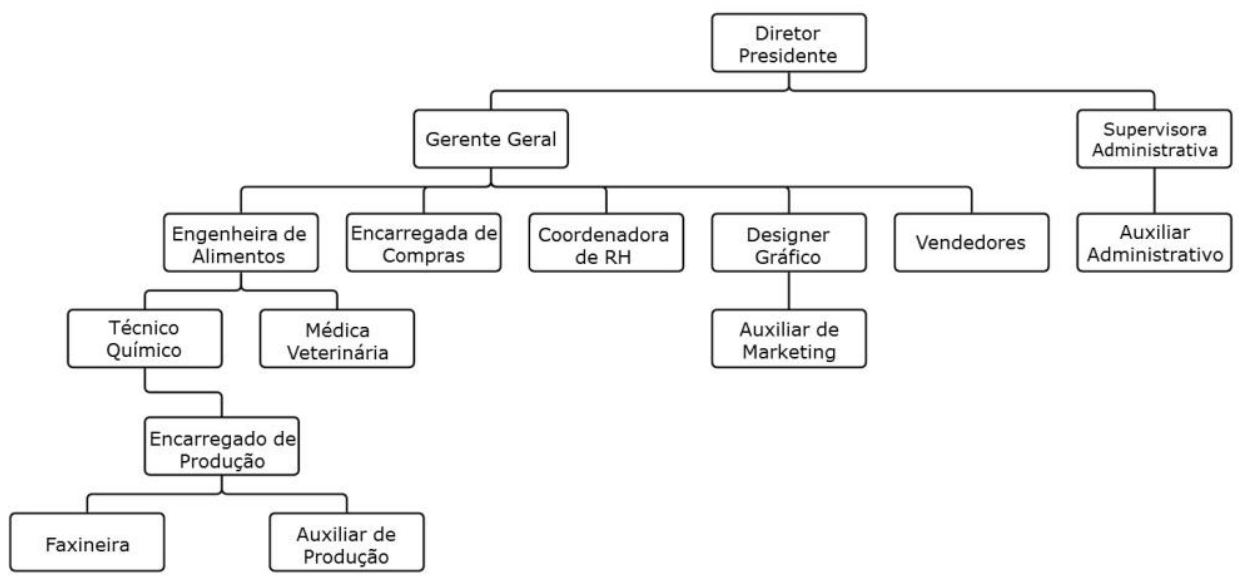

A empresa possui duas áreas de produção em sua instalação devido aos regulamentos dos órgãos controladores e ao processo de produção de cada produto. A primeira área recebe o nome de MAPA, pois segue as regulamentações do Ministério da Agricultura Pecuária e Abastecimento (MAPA) e é onde se produz itens de origem animal e vegetal. Já a segunda é chamada de ANVISA por seguir as normas da Agência Nacional de Vigilância Sanitária 
(ANVISA) e é o local em que são produzidos os alimentos, vitaminas e minerais em cápsulas, suplementos alimentares, farináceos e solúveis. A empresa escolhida trabalha com linhas de produtos distintas, o que a faz possuir uma quantidade de mais de 250 itens diferentes.

\section{COLETA DE DADOS E INFORMAÇÕES}

Para a coleta de dados, foi realizada observação direta e foi elaborado um roteiro guia para ser utilizado durante a entrevista aberta e in loco, que envolveu desde colaboradores do chão de fábrica até a equipe de gestão. A entrevista foi conduzida a partir de quatro grandes tópicos. O primeiro envolve questões a respeito da própria empresa com dados históricos e organizacionais, enquanto as seguintes abrangem informações referentes à gestão de demanda, gestão de estoque e gestão de capacidade. As respostas obtidas serão processadas nos resultados do trabalho.

\section{ETAPAS DE IMPLEMENTAÇÃO DO PCP PARA O SISTEMA PRODUTIVO ESCOLHIDO}

Para a implementação do PCP, utilizou-se como base a metodologia de implantação e melhoria das atividades ligadas ao PCP proposta por Barros Filho e Tubino (1999), que partem de pontos iniciais básicos até a implementação do sistema final em pequenas empresas. A metodologia dos autores possui dez etapas, porém neste estudo foram adaptadas em oito fases, sendo elas: (i) Definição da equipe; (ii) Apresentação dos conceitos e da importância do PCP (junção das etapas 2 e 3 da metodologia de Barros Filho e Tubino (1999)); (iii) Caracterização do sistema produtivo; (iv) Condições especiais do sistema produtivo; (v) Levantamento de informações e análise do sistema produtivo atual (junção das etapas 6 e 7 da metodologia de Barros Filho e Tubino (1999)); (vi) Sistematização e simplificação das atividades; (vii) Definição dos requisitos e desenvolvimento do sistema de PCP; e (viii) Implementação do sistema.

$\mathrm{Na}$ etapa (iii) para a caracterização do processo produtivo, utilizou-se a metodologia proposta por MacCarthy e Fernandes (2000). Na etapa (vii), como alternativa para auxiliar a gestão da empresa, desenvolveu-se uma ferramenta computacional para edição de planilhas o Microsoft Office Excel.

\section{RESULTADOS E DISCUSSÕES}

O presente trabalho dará foco a implementação de um sistema de PCP na área ANVISA, por ser a linha produtiva em que saem os produtos de maior representatividade da empresa e que resultam em maior volume de produção e rentabilidade, representando mais da metade no número de unidades vendidas. As etapas para a implementação do PCP na empresa estão descritas a seguir e seguem, de forma adaptada, a metodologia mencionada em Barros Filho e Tubino (1999). 


\section{DEFINIÇÃO DA EQUIPE QUE SERÁ RESPONSÁVEL PELO PROJETO}

A equipe de implantação do PCP na Empresa $X$ pode ser constituída pelo gerente geral, técnico químico, encarregada pelas compras e encarregado de produção (Figura 1). A presença do gerente geral é crucial para o sucesso do projeto, pois este representará o apoio da alta administração, uma vez que o diretor presidente passa a maior parte do tempo no escritório comercial central da instituição. A presença do técnico químico se mostrou essencial para ligar o chão de fábrica e a administração da empresa, pois atua em várias áreas dentro da mesma e possui grande interação com todos da organização. Por fim, são igualmente importantes a encarregada pelas compras, por cuidar do processo de compra de materiais para a empresa e auxiliar no controle de estoque, e o encarregado de produção (Figura 1), por fiscalizar o processo produtivo. A escolha desses profissionais segue o sugerido por Barros Filho e Tubino (1999), Martins et al. (2015) e Cruz (2018), pois para a execução de planos de melhorias em uma organização é preciso que haja um grupo responsável por implantar e avaliar o desempenho dos envolvidos no processo de mudança e que este seja composto, por membros de todos os níveis hierárquicos.

\section{APRESENTAÇÃO DOS CONCEITOS E SENSIBILIZAÇÃO SOBRE A IMPORTÂNCIA DO PCP NA EMPRESA}

Como feito nos estudos de Fagundes e Pires (2013), Martins et al. (2015) e Cruz (2018), a realização de reuniões e palestras internas podem se mostrar meios efetivos e de baixo custo para aplicar nesta etapa. Por meio das reuniões e palestras os responsáveis pela implantação do PCP apresentarão para todos os colaboradores a necessidade do projeto que está sendo implantado, o atual estado da empresa, as mudanças pelas quais ela passará e o estado futuro que se pretende alcançar. Em seguida, devem ser realizados treinamentos para que os funcionários saibam os conceitos básicos ligados ao PCP.

\section{CARACTERIZAÇ̃̃O DO TIPO DE SISTEMA PRODUTIVO}

A melhor forma de compreender e gerenciar um sistema de produção é a sua classificação apropriada, pois é por meio dela que se entende o nível de complexidade necessário para planejar e controlar as atividades produtivas (Barros Filho e Tubino, 1999; Maccarthy e Fernandes, 2000). Dessa forma, dentro da etapa "Caracterização do tipo de sistema produtivo", seguindo os passos propostos em Barros Filho e Tubino (1999), será utilizada como metodologia a classificação proposta por MacCarthy e Fernandes (2000).

(i) Processo produtivo atual: Na área ANVISA são produzidos os chamados "Farináceos", que envolve os farináceos e solúveis e também as "Cápsulas", que é composto por comprimidos e produtos encapsulados, que passam pelo processo de encapsulamento na empresa, como também aqueles que já saem preenchidos do fornecedor, caso de alguns produtos terceirizados e de cápsulas oleosas. Ambos os processos estão expostos na Figura $2 \mathrm{com}$ o seu respectivo fluxo, que tem início na "Chegada do pedido do cliente Farináceos/Cápsulas" e fim na "Expedição". A produção é baseada nos pedidos dos clientes, que podem ser realizados presencialmente ou por meios de comunicação como telefone e $e$ - 
mail, sendo recebidos pelo setor de vendas quando se tratam de produtos próprios da empresa e pelo gerente geral quando são produtos terceirizados.

Figura 2 - Fluxograma dos processos produtivos dos farináceos e das cápsulas

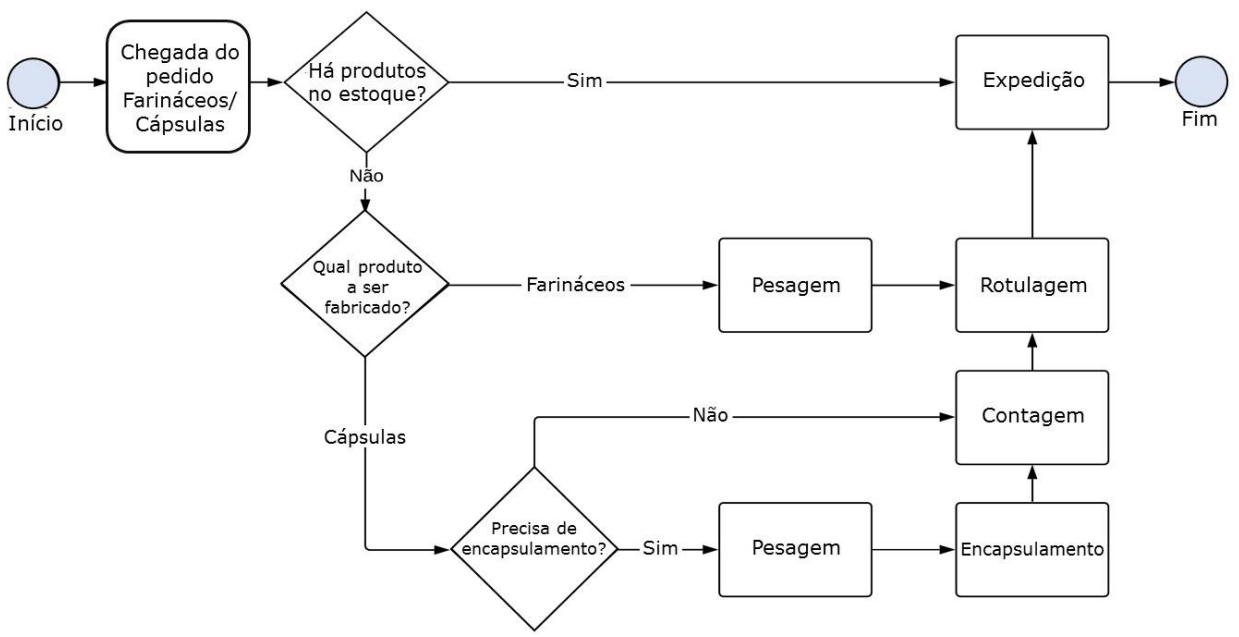

(ii) Caracterização geral da empresa e dos processos produtivos: esta etapa vai de (1) até (4). (1) Tamanho da empresa: a Empresa $X$ possui 44 funcionários, sendo considerada de pequeno porte, recebendo a classificação (S), de acordo com MacCarthy e Fernandes (2000); (2) Tempo de resposta: a empresa produz de acordo com os pedidos de produção e possui estoque de matéria-prima, o que a deixa com um tempo de resposta com classificação $(B=P L+D L)$, no qual PL é o lead time de produção e DL é o lead time de distribuição. (3) Repetitividade: o nível de repetitividade do processo produtivo dos dois grupos de produtos, Farináceos e Cápsulas, é o repetitivo (RP), a partir das definições, distinção e diversificação dadas por Fernandes e Godinho Filho (2010). (4) Nível de automação: o nível de automação empregado nos dois processos produtivos é o normal $(\mathbf{N})$, no qual o trabalho humano tem alto grau de participação no processo produtivo, sem a presença de equipamentos automáticos especializados.

(iii) Caracterização do produto: essa dimensão possui três variáveis. (1) Estrutura dos produtos da Empresa X: é de nível único e não exige montagem (SL). (2) Nível de personalização: é customizado (1) para os produtos terceirizados, isto é, os clientes definem todos os parâmetros do design do produto e padrão (4) para os produtos da empresa, pois os clientes não interferem no design do produto. (3) Número de produtos produzidos na empresa: trata-se de vários produtos (M).

(iv) Caracterização de processamento: essa dimensão possui três variáveis. (1) Tipo de layout, resultando na classificação (F) para a Empresa $X$ por ela ter sua área produtiva organizada com base nos processos realizados. (2) Tipo de estoque, sendo que no processo produtivo das Cápsulas há o estoque de matériaprima antes da primeira fase de produção (1), estoque intermediário entre os estágios de produção (2) e estoque após a última fase de produção (3). Por outro lado, o processo dos Farináceos possui estoque antes da primeira fase de produção (1) e depois da última fase de produção (3). Nos dois casos, considerase como estoque após a última fase de produção o produto final à espera do 
envio na Expedição, que como regra estabelecida pela empresa, o prazo varia e espera-se que seja no máximo de três dias. (3) Tipo de fluxo, que no caso das Cápsulas trata-se de um fluxo unidirecional (ANVISA, 2019) de processamento em múltiplos estágios, com máquinas iguais em paralelo, permitindo que tais estágios sejam pulados de acordo com o produto a ser fabricado (F7). O processo produtivo dos Farináceos, por sua vez, é classificado como (F6) por também possuir múltiplos estágios que possuem máquinas iguais em paralelo com o fluxo unidirecional, porém não permite que estágios sejam pulados.

(v) Caracterização da montagem: esta etapa está dividida em duas. (1) Tipos de montagem: a Empresa $X$ possui um tipo de montagem baseada em mistura (A1). (2) Tipos de organização do trabalho: trata-se de trabalho em equipe (T), no qual cada estação de trabalho é operada por uma equipe de trabalhadores.

(vi) Classificação final: após a definição das dimensões, utilizando os símbolos (/) para separar as dimensões e (_) para separar as variáveis, como definido por MacCarthy e Fernandes (2000), a classificação para os dois processos produtivos, a partir das etapas anteriores foi para o processo de fabricação dos Farináceos, $S / P L+D L / R P / N /\left\{\begin{array}{l}S L_{1} 1_{-} M \\ S L_{-} M\end{array}\right\} / F_{-} 1-3 \_F 6 / A 1 / T$ e para o processo de fabricação das Cápsulas $S / P L+D L / R P / N /\left\{\begin{array}{l}S L_{-} 1_{1} M \\ S L_{-}-M\end{array}\right\} / F_{-} 1-2-$ 3_F $7 / A 1 / T$.

De acordo com Fernandes e Godinho Filho (2010), a relação entre as variáveis vistas na classificação e a escolha de um sistema de PCP proposta por MacCarthy e Fernandes (2000) pode ser usada para identificar disfunções no sistema produtivo analisado por meio da comparação entre as características definidas pela empresa e as sugeridas pelos autores para o mesmo nível de repetitividade.

Dessa forma, ao comparar as sugestões de MacCarthy e Fernandes (2000) com os encontrados para a Empresa $X$, para os processos classificados como repetitivos, nota-se que há conformidade para as seguintes variáveis: nível de automação, tipos de estoque, tipos de montagem e nível de customização.

Contudo, percebe-se que existem disfunções no tempo de resposta, visto que MacCarthy e Fernandes (2000) recomendam um tempo de resposta baseado na produção para estoque, enquanto a empresa adota um tempo de resposta fundamentado na produção por ordem com estoque de matéria-prima. Outra disfunção encontrada foi no tipo de layout, uma vez que os autores recomendam a adoção do layout em grupo e o adotado pela empresa é o layout por processo, devido determinações da ANVISA (2019).

Quanto as classificações relacionadas a estrutura dos produtos, tamanho da empresa, número de produtos, tipos de fluxo e tipos de organização do trabalho nota-se que para a Empresa $X$ existe uma menor complexidade de implantação do PCP devido a sua classificação, e segundo MacCarthy e Fernandes (2000), o sistema de PCP sugerido é o Kanban ou o Period Batch Control (PBC). Alternativas para essas disfunções e sugestões do PCP serão discutidas na seção "Definição dos requisitos e desenvolvimento do sistema de PCP". 


\section{CONDIÇÕES BÁSICAS E ESPECIAIS DO SISTEMA PRODUTIVO}

$O$ setor em que a Empresa $X$ atua possui grande concorrência e a implantação de um sistema de PCP eficiente será a oportunidade de se destacar em relação aos demais e alcançar projeção internacional. Dessa forma, merecem destaque as seguintes verificações atuais da empresa: (i) As decisões de nível estratégico da empresa são tomadas principalmente pelo diretor presidente e o gerente geral, sem participação significativa dos níveis hierárquicos mais baixos (Figura 1); (ii) As decisões de médio e curto prazo são tomadas pelos profissionais do nível tático, que são responsáveis pela produção e gerenciamento do estoque, devendo passar pela aprovação do gerente geral, exceto em pequenos problemas do dia-a-dia, sendo as informações transmitidas verbalmente ao longo de toda a empresa, seja pessoalmente ou por meio de ramal telefônico; (iii) Os principais clientes da empresa são fixos e se tratam de pessoas jurídicas. Dentre as estratégias aumentar suas vendas há a utilização de redes sociais, participação em feiras, promoções diretas para os clientes, propagandas e a oferta de produtos como brinde. Grande parte dessas estratégias é adotada principalmente de abril a outubro, período de baixa demanda. Para buscar a fidelização dos clientes a empresa foca no pós-venda, que é o momento em que a equipe de vendas entra em contato com os clientes; (iv) Por se tratar de produto alimentício, a empresa deve seguir as regulamentações da ANVISA (ANVISA, 2019).

\section{LEVANTAMENTO DE INFORMAÇÕES E ANÁLISE DO SISTEMA PRODUTIVO ATUAL}

Nesta seção de análise do sistema produtivo haverá um enfoque na gestão de demanda, de capacidade e gestão de estoque.

Não há uma gestão de demanda na Empresa $X$, uma vez que a mesma não realiza cálculos de previsão de demanda e conta apenas com a percepção e experiência do gerente geral. A percepção dos colaboradores quanto à demanda é que a procura pelos produtos é maior no período de novembro a fevereiro.

Em relação aos estoques, a Empresa $X$ possui cerca de 40 fornecedores de matéria-prima e conta com o serviço de transportadoras para realizar as entregas. O processo de compra e recebimento de mercadorias ocorre toda semana, no entanto não possui período específico ou periodicidade, pois são realizados de acordo com a necessidade. A quantidade de unidades pedidas ao fornecedor varia de acordo com as vendas. A quantidade de matéria-prima em estoque é monitorada, de modo que quando a matéria-prima está acabando no estoque, o colaborador comunica à encarregada pelas compras, que por sua vez faz o pedido do item solicitado. Todavia, não há um planejamento quanto a verificação do estoque.

Quanto ao almoxarifado, esse é composto por várias salas nas quais as matérias-primas são organizadas em pilhas por prazo de validade, adotando a metodologia FIFO (primeiro a entrar/primeiro a sair). Todas as salas desse setor estão superlotadas oferecendo riscos de perdas dos materiais.

Observou-se também a ocorrência de estoque de produto em processo, caso das cápsulas, por não haver contra fluxo de material. Os produtos acabados ficam armazenados na sala de expedição, onde são empilhados e postos em linhas ao 
longo da área. O estoque de produto final é definido de acordo com a percepção dos responsáveis pela Expedição.

Em relação à gestão de capacidade, observou-se que os funcionários da área produtiva realizam somente uma pausa para almoço e, ocasionalmente, fazem hora extra. No entanto, em momentos de alta demanda, quando a empresa não tem capacidade de atender todos os pedidos com o funcionamento normal, essa necessidade se torna frequente, sendo preciso adotar o regime noturno, horas extras e trabalhos aos sábados. Ainda assim, há momentos em que a demanda não é suprida de maneira satisfatória. Por outro lado, em períodos de baixa demanda, alguns funcionários ficam ociosos. Não são realizadas avaliações de desempenho dos funcionários. Um posto de trabalho que limita a produção é a sala de encapsulamento, pois na mesma, há limite de manipulação de produtos simultaneamente devido as regulamentações da ANVISA (2019). Por fim, dificilmente ocorrem paradas não programadas na produção da empresa e isso se deve às manutenções programadas que ocorrem mensalmente de modo intercalado para não parar todo o processo produtivo, além das manutenções semestrais, que são mais profundas e também são realizadas em uma máquina por vez.

\section{OUTROS FATORES LIGADOS AO PROCESSO PRODUTIVO}

Os principais problemas internos enfrentados pela empresa são resultantes da falta de padronização do fluxo de informação, sendo transmitidos, na maioria das vezes, via ramal telefônico ou por anotações à mão em pedaços de papel o que pode resultar em erros.

\section{SISTEMATIZAÇÃO E SIMPLIFICAÇÃO DAS ATIVIDADES ATUAIS}

Como a empresa não possui nenhuma técnica de $P C P$, seu sistema de produção já é simples e as etapas produtivas se encontram bem definidas, o que precisa ser feito é organizar o fluxo de informação, um dos maiores problemas enfrentados pela empresa atualmente. É preciso também estabelecer ferramentas de gestão de demanda, estoque e capacidade. Aspectos similares foram verificados no estudo de Fagundes e Pires (2013).

\section{DEFINIÇÃO DOS REQUISITOS E DESENVOLVIMENTO DO SISTEMA DE PCP}

Ao analisar a empresa e seu sistema produtivo é possível perceber que há vários pontos possíveis de melhoria. Começando pelas atividades em longo prazo, é preciso a criação de um planejamento estratégico por parte do diretor da empresa para servir como base nas tomadas de decisão e no planejamento das atividades diárias. O planejamento em médio prazo já passa a ser de responsabilidade do nível tático, devendo este criar planos de ações com base em previsões mais detalhadas com o propósito de atingir as metas determinadas para longo prazo. Já as ações em curto prazo são ligadas ao nível operacional e este deve estar totalmente alinhado e ciente de suas funções para realizar e controlar de modo efetivo as ações determinadas pelo planejamento tático. 
Dessa forma, serão trabalhadas, de forma integrada, alternativas para estabelecer uma gestão de demanda, estoque, capacidade e o melhoramento do fluxo de materiais e informações, para que seja viável a implantação na Empresa $X$ e que esta possa ser usada como base para aplicação em outras organizações de pequeno porte. Como o presente estudo não busca a compra ou desenvolvimento de softwares, o foco foi dado em técnicas mais simples e fáceis de serem implantadas, de modo a poupar a empresa do processo conflitante de adaptação a um pacote computacional, buscando assumir primeiramente um nível organizacional melhor para depois sistematizar as atividades (BARROS FILHO; TUBINO, 1998). Sendo assim, a utilização de planilhas do Microsoft Office Excel atende de modo satisfatório as necessidades da empresa, tirando a obrigatoriedade de obtenção de algum pacote operacional pago. Metodologia similar foi utilizada nos estudos de Fagundes e Pires (2013) e Cruz (2018) para implementação do PCP em empresas de pequeno porte.

O sistema criado no presente trabalho será mostrado a seguir e disponibilizado para a Empresa X. Com a finalidade de facilitar o controle, optouse por criar planilhas separadas para os Farináceos e Cápsulas, de modo que informações, tendências e aspectos ligados aos tipos de produtos sejam de fácil percepção. Neste estudo serão expostas somente as planilhas relacionadas ao grupo das Cápsulas, uma vez que as planilhas dos produtos Farináceos são semelhantes.

Dentro dessa ferramenta de controle e planejamento criada, será observada a utilização das filosofias Kanban e Period Batch Control (PBC) em alguns momentos, uma vez que a base do presente trabalho não é implementar sistemas específicos na empresa de estudo, mas sim utilizar a base de ideias dessas filosofias como ferramentas simplificadoras que auxiliem na gestão de demanda, estoque e capacidade da empresa.

Outro destaque está relacionado a não necessidade de grande treinamento para todos os agentes para operacionalizar o sistema, como ocorre com o Kanban, conforme destacado em Tomazi et al. (2015), além das particularidades da implementação de um PBC "puro", que requer condições específicas para ser utilizado, como iguais tempos de processamento de todos os produtos (Fernandes; Godinho Filho, 2007).

Como já foi exposto, há uma falha na comunicação e no fluxo de informações dentro da empresa. O fluxo de informação será padronizado da seguinte forma, como visto na Figura 3: inicia-se com a chegada do pedido do cliente, pela equipe de vendas quando se tratar de produtos da própria empresa e pelo gerente geral em casos de produtos terceirizados; em sequência, este deve ser passado para a encarregada pelas compras que, de posse da planilha desenvolvida no presente estudo, irá verificar se o estoque de produto final, aba "Estoque de produto acabado", é suficiente para atender ao pedido; verificar o nível de estoque de matéria-prima na aba "Estoque de matéria-prima"; preencher a Ordem de Produção (OP) na aba "Ordem de produção" e a programação semanal da produção na aba "Programação da produção"; e atualizar as informações da planilha de controle. Essa ordem terá como base a filosofia Kanban, ou seja, caminhará pela empresa junto com o fluxo de materiais até a expedição e será o suporte para que os colaboradores realizem suas atividades. 
Figura 3 - Padronização do fluxo de informação

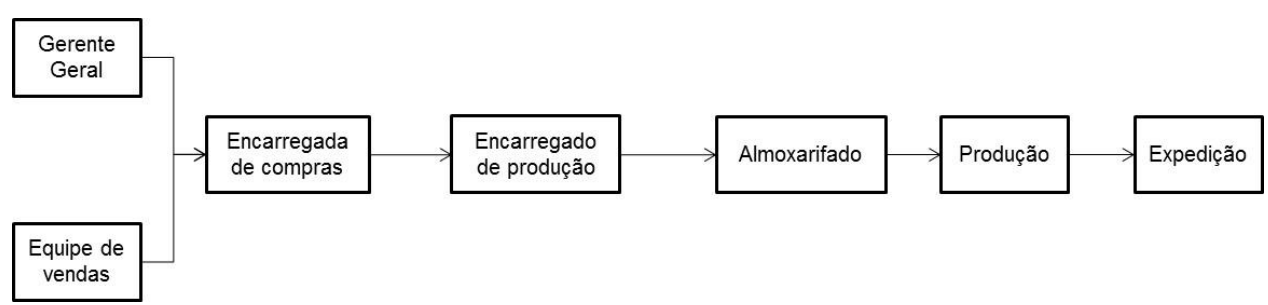

Para melhorar a comunicação, é necessária a padronização do fluxo de informações e a criação de um modelo de Ordem de Produção (OP) com as informações necessárias para todos os setores produtivos. A Ordem de Produção, apresentada na Figura 4, está na primeira aba da planilha. Parte dessa planilha é preenchida automaticamente a partir dos dados da aba "Produtos".

Neste momento, lotes de processamento devem ser criados para que haja o devido controle e planejamento na empresa. Quanto aos produtos do grupo das Cápsulas, este lote pode ser determinado pelo múltiplo de discos das máquinas encapsuladoras, que têm capacidade para encapsular 240 unidades por vez, auxiliando os colaboradores do Encapsulamento no controle da sua produção, contudo, para a correta definição deste valor faz-se necessário um estudo com base nos registros de produção. Já em relação aos Farináceos, essa quantidade pode ser calculada de acordo com o número de potes.

Quando o pedido do cliente chega, a encarregada pelas compras calcula quantos lotes de processamento serão necessários, imprime a quantidade de cartões de OP necessários para cada pedido e os encaminha para o encarregado de produção, que ficará responsável por liberar as ordens de acordo com o planejado e fiscalizar as etapas produtivas. Na Expedição, depois do preparo e entrega do pedido, um colaborador da área anotará a data de entrega e assinará na parte final do último cartão da OP por motivos de registro e controle. Por fim, essa ordem assinada deverá voltar para a encarregada pelas compras para que possa ser arquivada.

Figura 4 - Modelo de Ordem de Produção

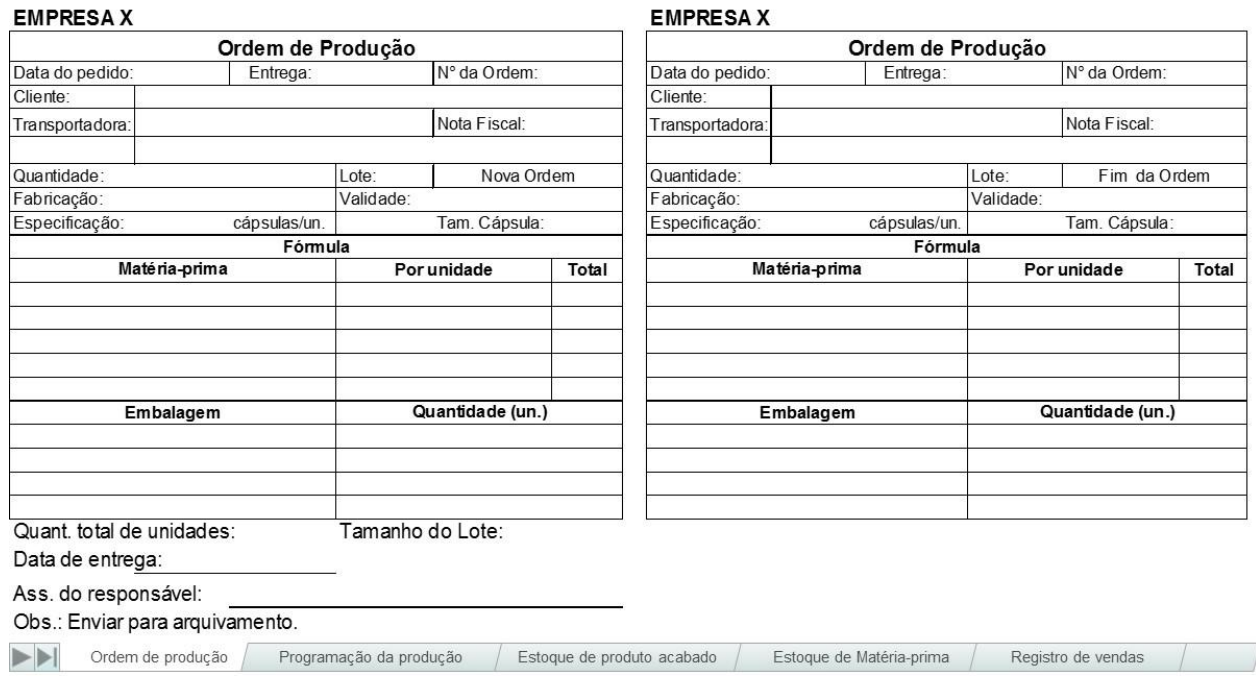


Aliado a isso, haverá no corredor que liga a sala de encapsulamento com a sala de contagem um quadro Kanban para o controle do estoque em processo entre a área de encapsulamento e contagem, facilitando a coordenação da produção na sala de encapsulamento (Figura 5). Cada cartão do quadro Kanban equivale à mesma quantidade de cápsulas que os cartões usados na OP. O quadro representa a quantidade de estoque disponível para a contagem de produtos processados pela sala de encapsulamento, dessa forma, quando o estoque de produtos estiver na quantidade máxima determinada, o quadro estará preenchido com todos os cartões, e, de acordo com que esse estoque vai diminuindo, tais cartões são retirados e começa-se a exibir as cores de fundo, verde, indicando a necessidade de produção, amarela e vermelha indicando a necessidade de matéria-prima para o próximo produto. A utilização desta técnica se faz necessária, pois do Encapsulamento é originado o estoque em processo mais expressivo.

Figura 5 - Quadro Kanban para o encapsulamento

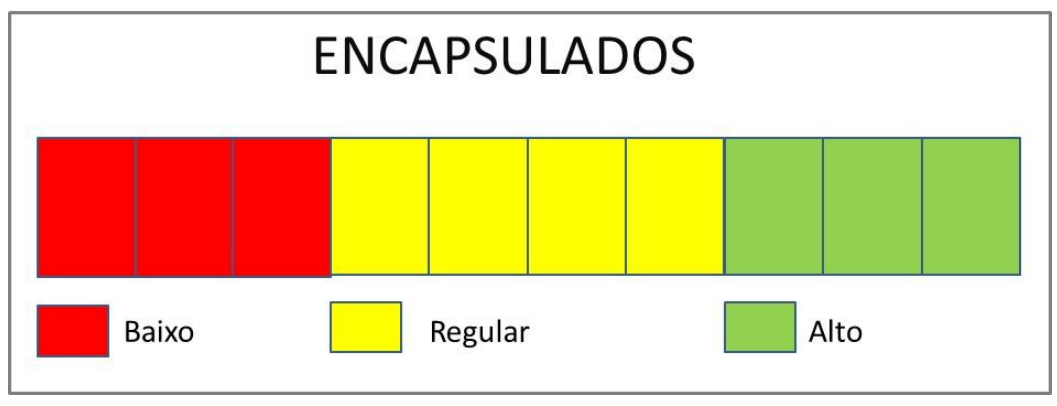

Na segunda aba está a programação da produção (Figura 6), onde é possível programar e sequenciar os pedidos ao longo da semana e do mês. Essa etapa inicia a atividade de gestão de demanda, uma vez que se começa a registrar a produção da empresa. Com o tempo, esses registros servirão de aporte para uma previsão de demanda, permitindo um planejamento prévio para os próximos períodos e também uma melhor gestão da capacidade produtiva da empresa. Como destacado, a Empresa $X$ possui um problema relacionado a gestão de capacidade, onde existem períodos de ociosidade e períodos de alta demanda. Atualmente, a empresa não trabalha com estoque, sendo vista como uma disfunção a partir da metodologia de MacCarthy e Fernandes (2000). Dessa forma, optou-se por propor uma metodologia de fazer para estoque.

Assim, a organização contará com um sistema misto, integrando um sistema puxado e um sistema empurrado. Para isso, será utilizada a proposta de MacCarthy e Fernandes (2000) tendo como base o PBC, associado ao plano mestre de produção (PMP) para controlar principalmente a parte empurrada da produção. Quando a demanda estiver alta a produção será apenas puxada. Em períodos de baixa, serão utilizados ambos os tipos de produção, puxada e empurrada. Essa alternativa é bastante interessante para a empresa, pois a mesma já possui área física para estocagem de produto acabado e mão de obra experiente no almoxarifado. Destaca-se também, que o alto uso de horas extras em períodos de alta demanda será diminuído ou inexistente, resultando em menor cansaço dos funcionários e maior produtividade. 
Figura 6 - Programação da produção

\begin{tabular}{|c|c|c|c|c|c|c|c|c|c|c|c|c|c|}
\hline \multicolumn{7}{|c|}{ Mês 1} & \multicolumn{7}{|c|}{ Mês 2} \\
\hline Produto & Quant. Potes & Seg. & Ter. & Quar. & Quin. & Sext. & Produto & Quant. Potes & Seg. & Ter. & Quar. & Quin. & Sext. \\
\hline \multicolumn{7}{|c|}{ Semana 1} & \multicolumn{7}{|c|}{ Semana 1} \\
\hline & & & & & & & & & & & & & \\
\hline & & & & & & & & & & & & & \\
\hline & & & & & & & & & & & & & \\
\hline \multicolumn{7}{|c|}{ Semana 2} & \multicolumn{7}{|c|}{ Semana 2} \\
\hline & & & & & & & & & & & & & \\
\hline & & & & & & & & & & & & & \\
\hline & & & & & & & & & & & & & \\
\hline \multicolumn{7}{|c|}{ Semana 3} & \multicolumn{7}{|c|}{ Semana 3} \\
\hline & & & & & & & & & & & & & \\
\hline & & & & & & & & & & & & & \\
\hline & & & & & & & & & & & & & \\
\hline \multicolumn{7}{|c|}{ Semana 4} & \multicolumn{7}{|c|}{ Semana 4} \\
\hline & & & & & & & & & & & & & \\
\hline & & & & & & & & & & & & & \\
\hline & & & & & & & & & & & & & \\
\hline$\rightarrow$ Order & de produção & Prograr & açãa d’ & produção & Estoc & ue de proc & uto acabado & Estoque de Mate & ria-prima & & gistro de v & ndas & \\
\hline
\end{tabular}

As abas 3 e 4 estão relacionadas a estoque de produto acabado e matériaprima/embalagens, respectivamente. Na terceira aba está o estoque de produto acabado (Figura 7), que não será significativo em períodos de alta demanda, porém será essencial nos períodos de baixa, justificando seu planejamento e controle.

Nessa aba estão contidas informações como estoque de segurança, estoque máximo, o registro de entrada (quando há produção para estoque) e saída (quando o produto é vendido) e o estoque atual.

Há ainda uma coluna chamada "Ação", que indica automaticamente com a mudança de cor da célula e o aparecimento da ordem "produzir", quando o estoque de algum produto fica abaixo do estoque de segurança, facilitando o controle e a percepção por parte da encarregada de compras.

$\mathrm{Na}$ quarta aba está o estoque de matéria-prima (Figura 8), dispondo de informações como estoque de segurança, entrada (preenchida quando é realizada a compra da matéria-prima), saída (que representa a utilização do material para a produção), estoque máximo, estoque atual, além da coluna "Ação" que indica quando a quantidade atual na empresa é menor que a quantidade mínima definida e exige o pedido de compra.

Nessa aba estão as informações tanto para as matérias-primas quanto para as embalagens, porém as duas foram divididas em duas tabelas para facilitar a visualização para quem for utilizá-la.

Para ambas as abas, neste primeiro momento deve-se iniciar o preenchimento das informações a partir de um inventário de estoque, que segundo Souza Júnior e Fernandes (2016), tornam-se fundamentais para a gestão de estoque. Já as informações relacionadas a estoque de segurança e máximo, para cada produto serão adquiridas de acordo com a experiência do gestor. Após os registros, em períodos futuros, essas informações poderão ser calculadas. 
Figura 7 - Estoque de produto acabado

\begin{tabular}{|l|l|l|l|l|l|l|c|}
\hline Código & Produto & $\begin{array}{c}\text { Estoque de } \\
\text { Segurança (un.) }\end{array}$ & $\begin{array}{c}\text { Estoque } \\
\text { Máximo (un.) }\end{array}$ & Entrada (un.) & Saída (un.) & $\begin{array}{c}\text { Estoque } \\
\text { atual (un.) }\end{array}$ & Ação \\
\hline & & & & & & & \\
\hline & & & & & & & Produzir \\
\hline & & & & & & & \\
\hline & & & & & & Produzir \\
\hline
\end{tabular}

Figura 8- Estoque de Matéria-prima e embalagem

\begin{tabular}{|c|c|c|c|c|c|c|c|c|c|c|c|c|c|}
\hline \multicolumn{7}{|c|}{ ESTOQUE DE MATÉRIA-PRIMA (KG) } & \multicolumn{7}{|c|}{ ESTOQUE DE EMBALAGEM (UN.) } \\
\hline Item & \begin{tabular}{|l|} 
Estoque de \\
Segurança
\end{tabular} & $\begin{array}{l}\text { Estoque } \\
\text { máximo }\end{array}$ & Entrada & Saída & $\begin{array}{c}\text { Estoque } \\
\text { atual }\end{array}$ & Ação & Embalagem & \begin{tabular}{|l|} 
Estoque de \\
Segurança
\end{tabular} & $\begin{array}{l}\text { Estoque } \\
\text { máximo }\end{array}$ & Entrada & Saída & $\begin{array}{c}\text { Estoque } \\
\text { atual }\end{array}$ & Ação \\
\hline & & & & & & & & & & & & & Compra \\
\hline & & & & & & Compra & & & & & & & Compra \\
\hline & & & & & & & & & & & & & \\
\hline & & & & & & Compra & & & & & & & \\
\hline & & & & & & & & & & & & & \\
\hline$\rightarrow$ Ord & produçắo & Programaç & ẵo da produ & & Estoque & de produ & acabado & Estoque de Mat & téria-prima & & istroder & vendas & \\
\hline
\end{tabular}

Na quinta aba está o registro de vendas mensal (Figura 9), que servirá, a princípio, somente como base para registro de informações de venda, possibilitando no futuro a utilização desses dados para a realização de previsões de demanda. Dentre os métodos de previsão possíveis, optou-se sugerir a utilização de métodos quantitativos baseados em séries históricas que apresentem a componente sazonal mencionada pelos colaborares da empresa, visto que, segundo Henning, Alves e Konrath (2010) e Veríssimo et al. (2012), esta técnica baseia-se em observações passadas para se obter informações sobre o seu padrão de comportamento no futuro, permitindo conhecer e entender como a demanda se comporta ao longo do tempo.

Recomenda-se que embaixo do registro de cada mês seja colocada uma observação quando houver a ocorrência de promoções, descontos ou outros fatores que possam alterar a demanda para serem levados em consideração durante o processo de previsão. Dessa forma, a experiência do gestor aliada a utilização de registros de dados quantitativos aumentará a acurácia dos resultados de previsão, como mostrado em Meneghini et al. (2018). As informações sobre nota fiscal e transportadora são para controle dos destinos e transporte dos produtos, para caso seja necessário realizar algum recall ou solucionar problemas.

Figura 9- Registro de venda

\begin{tabular}{|l|c|c|c|c|c|c|c|c|c|c|c|}
\hline \multicolumn{9}{|c|}{ Janeiro } & \multicolumn{9}{c|}{ Fevereiro } \\
\hline Código Produto & $\begin{array}{c}\text { Quantidade } \\
\text { Potes }\end{array}$ & $\begin{array}{c}\text { Quantidade } \\
\text { Cápsulas }\end{array}$ & Cliente & Nota Fiscal & Transportadora & Código & $\begin{array}{c}\text { Quantidade } \\
\text { Potes }\end{array}$ & $\begin{array}{c}\text { Quantidade } \\
\text { Cápsulas }\end{array}$ & Cliente & Nota Fiscal & Transportadora \\
\hline & & & & & & & & & & & \\
\hline & & & & & & & & & & & \\
\hline & & & & & & & & & & & \\
\hline
\end{tabular}

A sexta aba (Figura 10) contém todos os produtos da empresa, incluindo a relação de matérias-primas, embalagens e fornecedores para cada produto. Como citado anteriormente, é com base nessa aba que a OP é preenchida, basta 
selecionar o produto desejado e clicar no botão "Preencher" que a ordem de produção receberá as informações contidas nesta aba, isto é, as informações quanto ao tamanho da cápsula, a quantidade de cápsulas em cada pote, a fórmula do produto e a embalagem.

Figura 10- Registro de produtos da Empresa X

\begin{tabular}{|l|l|l|l|l|l|l|l|l|}
\hline \multicolumn{2}{|r|}{ Preencher } & \multirow{2}{*}{$\begin{array}{c}\text { Quant. Cápsulas } \\
\text { por pote }\end{array}$} & \multicolumn{3}{c|}{ Fórmula } & \multicolumn{2}{c|}{ Embalagem } \\
\cline { 1 - 5 } & Código & Produto & Tam. Cápsulária-prima & Quant. (kg) & Fornecedor & Nome & Fornecedor \\
\hline & & & & & & & & \\
\hline & & & & & & & & \\
\hline & & & & & & & & \\
\hline & & & & & & & & \\
\hline
\end{tabular}

A última aba (Figura 11) contém todos os fornecedores ligados a empresa, os produtos que fornecem e seu contato, servindo como apoio para o colaborador que precisar dessas informações de modo mais rápido.

Figura 11- Lista de fornecedores da Empresa X

\begin{tabular}{|c|c|c|c|}
\hline Fornecedor & Produtos & Telefone & E-mail \\
\hline & & & \\
\hline & & & \\
\hline & & & \\
\hline & & & \\
\hline
\end{tabular}

Dessa forma, com o auxílio da presente ferramenta, o controle da quantidade em estoque de matéria-prima, produto final, bem como o registro de entrada e saída de cada um será de responsabilidade majoritariamente de uma única pessoa, a encarregada pelas compras, facilitando a tomada de decisão, acabando com os pedidos de produção por parte da expedição e evitando erros de gestão.

\section{IMPLANTAÇÃO DO SISTEMA}

A última etapa é a implantação do sistema e aplicação das melhorias, porém, como destacado por Barros Filho e Tubino (1999), mesmo podendo ser considerada como a etapa mais fácil, ela ainda é a mais importante e demorada. Por isso, para se evitar problemas ligados à mudanças súbitas e precipitadas, as alterações propostas ainda não foram totalmente implantadas. Estudos similares que utilizaram essa mesma metodologia verificaram também que essa é uma etapa a ser analisada em longo prazo (FAGUNDES; PIRES, 2013; CRUZ, 2018). Contudo, mesmo sem a aplicação prática, é possível perceber que o sistema tem potencial para auxiliar a empresa no seu processo de planejamento e controle da produção, resolvendo alguns problemas comuns na empresa, relacionados a gestão de demanda, gestão de estoque, gestão de capacidade e organização. Para isso, reuniões e palestras com os responsáveis pela implantação do PCP vêm sendo realizadas durante todo o trabalho a fim de minimizar a resistência as mudanças sugeridas. 


\section{CONSIDERAÇÕES FINAIS}

Com o presente trabalho foi possível apresentar um modelo de implantação e melhorias ligadas ao $\mathrm{PCP}$, a partir de problemas de gestão verificados na Empresa X.

Inicialmente, o presente trabalho verificou que a Empresa $X$ não possui implementado um sistema de PCP o que acarreta problemas de gestão de demanda e de capacidade, onde a falta de registro de demanda não possibilita uma programação da produção, verificando-se períodos com capacidade ociosa e outros com trabalho em capacidade máxima. Verificou-se também que não há um planejamento quanto a verificação do estoque e ordens de compra.

A utilização de uma metodologia de classificação mais detalhada e profunda como a de MacCarthy e Fernandes (2000) se mostrou muito efetiva na busca pelo conhecimento sobre empresa, suas disfunções e os sistemas de coordenação de ordem com base no PCP mais ideal para o processo produtivo estudado. Com a implantação do modelo proposto por Barros Filho e Tubino (1999) foi possível criar sistemas simples e eficazes de planilha eletrônica no âmbito do PCP baseados em técnicas como Kanban e PBC.

O fator humano também se destacou como importante para a empresa de um modo geral, mas principalmente nos períodos de mudanças, uma vez que as etapas iniciais do processo de implantação do PCP na empresa envolvem a definição do melhor grupo para coordenar as transformações, o compartilhamento de conhecimento e a sensibilização de todos. Assim, torna-se fundamental para a implantação do PCP a participação de pessoas chave, como o técnico químico, agindo como elo entre todos os níveis hierárquicos e a encarregada pelas compras, como auxílio para a gestão.

Mesmo não sendo possível avaliar, em curto prazo, a implantação de todas as etapas descritas neste trabalho, é possível verificar a aplicação da metodologia de investigação, análise, sugestões de alterações e simplificações em processos produtivos e de gestão, o que resultará em benefícios para a organização de estudo e também para pesquisas relacionadas a empresas de pequeno porte, com características similares as da empresa estudada. 


\title{
Production planning and control in a small food company
}

\begin{abstract}
The Production Planning and Control (PPC) is fundamental for a company to define its goals and strategies in the market in order to create a management plan for its good performance. Thus, the objective of the present study is to carry out checks associated with the management of demand, stock and capacity, proposing the implementation of a PPC system in a small food company, located in the state of Espírito Santo, Brazil. This study used as reference the methodologies for PPC implementation and processes analysis consolidated in the literature. Visits in loco, and direct observations of the production process were realized during the execution of this work. The results show that the company does not carry out formal procedures such as the management of demand and stock, measurements of the production capacity, and well-defined routines, resulting in some problems associated with the production process. In this study, it was used some implementation steps reported in the literature in order to provide initial strategies for the PPC implementation, mainly based on the development of electronic spreadsheets associated with the Kanban philosophy and the Period Batch Control, without the need to purchase any management software. Additionally, the investigation, analysis, suggestions and simplifications of the production processes carried out in the present work can be used as a source for future researches considering similar situations of the studied company.
\end{abstract}

KEYWORDS: PPC implementation. PPC Activities. Food company. Small company. 
ALMEIDA, R. P.; ROMANZINI, F.; WERNER, L. Planejamento da capacidade de produção na indústria plástica: uma abordagem baseada em previsão de demanda e níveis de capacidade. Revista Produção Online, v. 16, n. 3, p. 10331057. 2016. crossref

ANVISA - Agência Nacional de Vigilância Sanitária. Biblioteca de alimentos. 2019. Disponível em: http://portal.anvisa.gov.br/alimentos/legislacao (acesso em 23 jun. 2019).

ARAÚJO, G. C.; SILVA, J. P. Z.; SOUZA, L. R.; LOUREIRO, M. B.; FERONI, R. C. Previsão de demanda e análise simplificada da gestão de estoque aplicadas a uma empresa do setor alimentício. Brazilian Journal of Production Engineering, v. 4, n. 2, p. 48-64. 2018.

BARBOSA, E. S.; SANTOS, M. S.; NETO LOPES, V. M. A Importância Do PCP (Planejamento e Controle da Produção) para a competitividade em indústrias de Juazeiro da Bahia. Id on Line Rev.Mult. Psic., v. 13, n. 47, p. 89-108. 2019. crossref

BARROS FILHO, J. R.; TUBINO, D. F. O Planejamento e Controle da Produção nas Pequenas Empresas - Uma Metodologia de Implantação. In. ANAIS DO $18^{\circ}$ ENCONTRO NACIONAL DE ENGENHARIA DE PRODUÇÃO, Niterói. 1998.

BARROS FILHO, J. R.; TUBINO, D. F. Implantação do planejamento e controle da produção em pequenas e médias empresas. In. ANAIS DO 19 ENCONTRO NACIONAL DE ENGENHARIA DE PRODUÇÃO, Rio de Janeiro. 1999.

BESSONI, A. P.; RODRIGUES, J. B.; SANCHETA, L. N; DUTRA, M. G.; FERONI, R. C. Análise de série temporal com previsão de vendas e verificação simplificada da gestão de estoque: um estudo de caso em uma revendedora de gás. Brazilian Journal of Production Engineering, v. 4, n. 4, p. 44-69. 2018.

CASTRO, T. R. Planejamento e controle da produção em uma indústria de margarinas. Revista Gestão Industrial, v. 14, n. 3, p. 1-22. 2018. crossref

CRUZ, M. S. Aplicação de um modelo de planejamento e controle de produção em uma pequena empresa de esquadrias de alumínio. Administração-Pedra Branca, 2018.

FAGUNDES, L. D.; PIRES, J. Implantação do Planejamento e Controle da Produção em uma Microempresa de Usinagem e Ferramentaria de Molde. In. ANAIS DO $33^{\circ}$ ENCONTRO NACIONAL DE ENGENHARIA DE PRODUÇÃO, Salvador. 2013. 
FERNANDES, F. C. F.; GODINHO FILHO, M. Planejamento e controle da produção: dos fundamentos ao essencial. São Paulo: Editora Atlas S/A, 2010.

FERNANDES, F. C. F.; GODINHO FILHO, M. Sistemas de coordenação de ordens: revisão, classificação, funcionamento e aplicabilidade. Revista Gestão \& Produção, v. 14, n. 2, p. 337-352. 2007. crossref

FERREIRA, V. E. S.; CARMO, B. B. T.; OLIVEIRA, A. G. Proposta de um sistema de informação para a gestão de inventário e o direcionamento das campanhas de coleta de sangue. Gestão \& Produção, v. 26, n. 2. 2019. crossref

GODINHO FILHO, M.; FERNANDES, F. C. F. Uma análise dos sistemas de planejamento e controle da produção em uma grande empresa de materiais de escrita. In. ANAIS DO $22^{\circ}$ ENCONTRO NACIONAL DE ENGENHARIA DE PRODUÇÃO, Curitiba, 2002.

GOMES, J. A.; CAMILO, E. Planejamento e controle da produção (PCP): ferramenta estratégica de competição em pequenas empresas. In. II SEMINÁRIO EMPRESARIAL E II JORNADA DE TI DA FACULDADE CIDADE VERDE, Maringá. 2014.

GOMES, R. P.; MILAN, W. W. Gestão de estoque pelo método do estoque máximo-mínimo em uma empresa de médio porte do ramo de revenda de combustível em Carneirinho- MG. Revista Organizações e Sociedade, v. 6, n. 5, p. 19-36. 2017.

HENNING, E.; ALVES, C. C.; KONRATH, A. C. Previsão de vendas de rodízios para móveis em uma empresa de médio porte. In. ICPR AMERICAS - 5th Americas International Conference on Production Research, Bogotá. 2010.

SOUZA JÚNIOR, J. C.; FERNANDES, S. M. Tecnologias e metodologias aplicadas ao gerenciamento de estoque de um hospital público, J. health inform, v. 8, p. 227236. 2016.

MACCARTHY, B. L.; FERNANDES, F. C. F. A multi-dimensional classification of production systems for the design and selection of production planning and control systems. Production Planning \& Control, v. 11, n. 5, p. 481-496. 2000. crossref

MARTINS, A. S.; ARAÚJO, M. J. A.; LISPOA, E. G.; BORGES, F. Q.; PINHEIRO, J. Q. As dificuldades de implantação de sistemas de planejamento e controle de produção: um estudo de caso em uma empresa fabricante de colchões.

Observatorio de la Economía Latinoamericana, n. 209. 2015. 
MENEGHINI, M.; ANZANELLO, M.; KAHMANN, A.; TORTORELLA, G. L. Quantitative demand forecasting adjustment based on qualitative factors: case study at a fast food restaurant. Sistemas \& Gestão, v. 13, n. 1, p. 68-80. 2018. crossref

MOTTA, M. P. O.; GOMES, J. P. H. Capacidade produtiva e eficiência de processo: um estudo de caso em uma confecção de moda fitness. Revista Interdisciplinar Pensamento Científico, v. 2, n. 2, p. 288-341. 2017. crossref

NUNES, D. P.; COSTA, F.; BUENO, R. E.; FERNANDES, S. Análise de capacidade produtiva para uma demanda futura de 'carrinho de compras sustentável. South American Development Society Journal, v. 4, n. 12. 2018. crossref

PASQUINI, N. C. Planejamento e controle da produção (PCP): estado da arte. Revista Tecnológica da Fatec Americana, v. 3, n. 2, p. 81-97. 2015.

SAGAWA, J. K.; SOUZA, J. F. C.; ARAÚJO, L. R.; MARQUES, M.C.; NOGUEIRA, W.S. Aplicação da Metodologia Enxuta em uma empresa dos ramos da saúde, alimentos e farmacêuticos. Revista GEPROS, v. 11, n. 2, p. 173. 2016. crossref

SILVA, R. B.; WERNER, L. Utilização do Processo Hierárquico Analítico para priorização de variáveis a serem utilizadas na previsão de demanda no setor de suplementação animal. Produto \& Produção, v. 17, n. 1, p. 64-78. 2016. cross ref

SLACK, N.; Chambers, S.; Johnston, R. Administração da produção, São Paulo: Atlas. 2015.

TOMAZI, L. F.; BONOMINI JÚNIOR, R. A.; ROSSETTO, R. M.; HOLSTAK, D.; SILVA, G. G. M. P. Sistema de Sincronização de Ordens Operacionalizado por Cartões Kanban em uma Empresa de Cerâmica Vermelha. Cerâmica Industrial, v. 20, n.3, p. 23-29. 2015. crossref

VERísSIMO, A. J; ALVES, C. C; HENNING, E; AMARAL, C. E; CRUZ, A. C. Métodos estatísticos de suavização exponencial Holt-Winters para previsão de demanda em uma empresa do setor metal mecânico. Revista Gestão Industrial, v. 8, n. 4 , p. 154-171. 2012. crossref 
Recebido: 23 Jan. 2020

Aprovado: 08 Out. 2020

DOI: 10.3895/gi.v16n1.11537

Como citar:

RODRIGUES, J.B. et al. Modelo para a formatação dos artigos a serem submetidos à Revista Gestão Industrial. R. Gest. Industr., Ponta Grossa, v. 16, n. 1, p. 78-98, Jan./Mar. 2020. Disponível em:

https://periodicos.utfpr.edu.br/revistagi

Correspondência:

Jocicleia Bissaro Rodrigues

Rod. Governador Mário Covas, BR-101 - km 60 - Bairro Litorâneo, São Mateus, Espírito Santo, Brasil. Rita de Cassia Feroni

Rod. Governador Mário Covas, BR-101 - km 60 - Bairro Litorâneo, São Mateus, Espírito Santo, Brasil. Direito autoral: Este artigo está licenciado sob os termos da Licença Creative Commons-Atribuição 4.0 Internacional.

\section{(c) (1)}

